\title{
Spectrum of Oral Cavity Lesions and its Clinico-Histopathological Correlation
}

\author{
Deepshikha Gaire, ${ }^{1}$ Anil Dev Pant, ${ }^{2}$ Daisy Maharjan, ${ }^{3}$ Usha Manandhar ${ }^{2}$ \\ ${ }^{1}$ Department of Pathology, Paropakar Maternity and Women's Hospital, Thapathali, Kathmandu, Nepal; \\ ${ }^{2}$ Department of Pathology, Institute of Medicine, Maharajgunj, Kathmandu, Nepal; ${ }^{3}$ Department of Pathology, Pokhara \\ Academy of Health Science, Pokhara, Nepal.
}

\begin{abstract}
Introduction: Oral cavity lesions comprise a wide spectrum of diseases varies from non-neoplastic to neoplastic. Clinical evaluation alone is insufficient for proper diagnosis in most of the cases. So, histopathological examination is gold standard method for diagnosis and management of patient accordingly.

Objective: The present study was done to evaluate the histopathological spectrum of oral cavity lesions and compare them in relation to age, sex, site, clinical features, risk factors and clinical diagnoses.

Methods: This prospective cross sectional study enrolled 127 cases of oral biopsies which were received at Department of Pathology, Tribhuvan University and Teaching Hospital, Kathmandu Nepal, from May 2018 to April 2019 for histopathological examination. Specimens were fixed in $10 \%$ formalin and subjected for tissue processing and Hematoxylin and Eosin stained sections. Data entry and analysis was done by using SPSS 24 version where frequency and percentile were calculated.

Results: Total cases were 127 with slight female predilection and age group of 50-60 years (mean age of 44.24 years) were commonly affected. Tongue being most common site, frequently lesions presented as swelling. Most of the lesions were non neoplastic comprising 45\% whereas malignant lesions comprised 23.6\%. Smoking increased risk of malignancy by 2 fold. The most common benign lesions were squamous papilloma \& fibroepithelial polyp whereas malignant lesion was squamous cell carcinoma. Sixty percent of clinical diagnoses didn’t show correlation.

Conclusions: Oral cavity lesions have wide spectrum of distribution in age, sex, site and clinical presentation. Initially oral lesions may present with subtle symptoms which may cause underdiagnosis. Thus, histopathological diagnosis is a must to rule out malignancy.
\end{abstract}

Keywords: Clinical presentation; correlation; oral cavity; risk factors.

\section{INTRODUCTION}

Oral cavity begins at the vermillion border of the lips and is delimited above by the hard palate, below by the floor of the mouth, laterally by the buccal mucosa (inner cheek) and posteriorly by the retromolar trigone and glossopalatine fold. A wide variety of

\footnotetext{
Correspondence

Dr Deepshikha Gaire

Email:dipc62@gmail.com

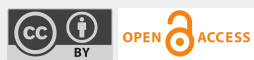

Citation

Gaire D, Pant AD, Maharjan D, Manandhar U. Spectrum of Oral Cavity Lesions and its Clinico-Histopathological Correlation. Nepal J Health Sci. 2021 Jul-Dec; 1(2): 42-7.
}

lesions ranging from non-neoplastic to neoplastic involve the oral cavity. Tumor may originate from epithelial tissue, connective tissue, muscle tissue, nerve tissue and vessels. Oral cancer is one of the six most frequently occurring cancers and squamous cell carcinoma (SCC) is the common type. ${ }^{1}$ Most people with oral and oropharyngeal cancers have history of tobacco use and the risk of developing these cancers is related to frequency and duration they smoked or chewed. $^{2}$

However, the nature of the oral cavity lesions cannot be confirmed by clinical examination alone so, it is very important to have definitive diagnosis and 
provide treatment accordingly. So, histopathological examination detects premalignant and malignant lesions at earlier stage.

Thus, main aim of this study is to find out nature of lesions, its predilection with age, sex, site, association with risk factors and clinico-histopathological correlation.

\section{METHODS}

This study was a hospital based cross sectional prospective study done for one year from $1^{\text {st }}$ May 2018 to $30^{\text {th }}$ April 2019. All the patient presenting to Department of Pathology, histopathology unit, Tribhuvan University Teaching Hospital, Kathmandu, Nepal for histopathological examination of oral cavity lesions were included in study. Inclusion criteria's were specimens which were adequate and representative of the lesion and resected surgical specimens like wide local excision, incisional biopsies, punch biopsy, wedge biopsies, surgical excision, hemi-glossectomy whereas exclusion criteria includes inadequately preserved specimens; neoplasm arising from nasopharynx or oropharynx; bone tumors of mandible, maxilla and odontogenic lesions.

Tissue biopsies received in $10 \%$ formalin in the Department of Pathology were subjected to gross

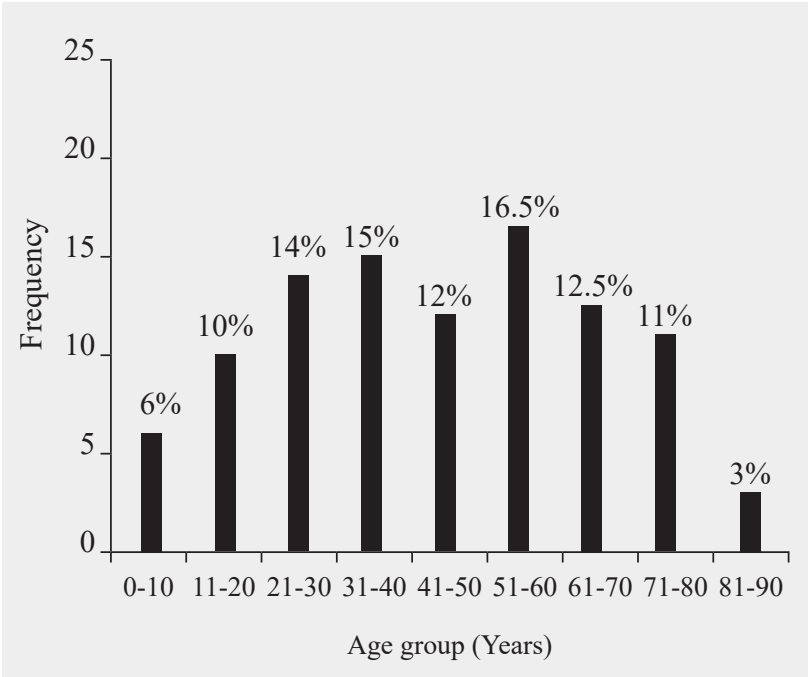

Figure 1: Age wise distribution of oral cavity lesions examination and the size, appearance, external surface, cut surfaces were noted. Representative sections were taken, processed, embedded in paraffin block and sliced to obtain five micron thick sections. The slides were then stained with routine hematoxylin and eosin stain and other special stains wherever required. All sections were examined for the pathological lesions.

A structured questionnaire was used on all the study population and filled up. Information obtained was entered into master chart. Computer software "statistical package for social science" (SPSS) 24 was used for processing and analysis of the data.

Approval from the Institutional Review Board of Institute of Medicine (Ref No. 356), Tribhuvan University Teaching Hospital and Research Department was taken. All the individuals in the study were informed and explained about the study prior to enrollment. Written informed consent was obtained.

\section{RESULTS}

Most commonly affected age group was 51-60 years, which comprised 21 cases $(16.5 \%)$ and least affected range was 81-90years which comprised 4 cases (3\%) as shown in figure 1 . Of total 127 patients included in this study, $66(52 \%)$ were females and $61(48 \%)$ were males.

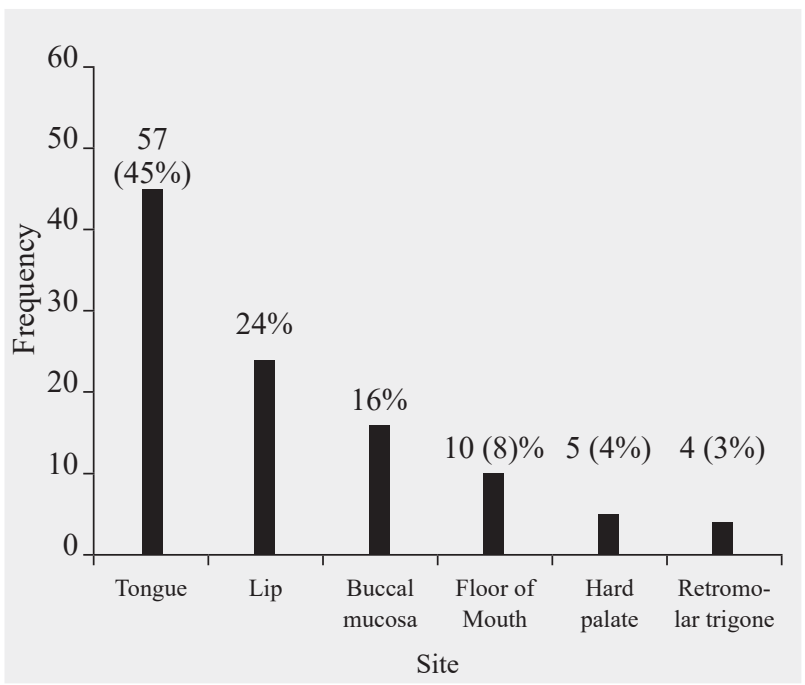

Figure 2: Site-wise distribution of oral cavity lesions. 
The most commonly affected site was tongue which comprised 57 cases (45\%) followed by lip 31 cases (24\%) (Figure 2). The least affected site was retromolar trigone which comprised 4 cases $(3 \%)$.

The most common lesion was non neoplastic which comprised 57 cases (45\%), followed by benign (24.4\%, 31 cases). Malignant lesions constituted 30 cases $(23.6 \%)$ whereas premalignant comprises 9 cases (7\%). Malignant lesions showed male (13.5\%) preponderance while non-neoplastic lesions commonly affect females. Benign and premalignant lesions showed almost equal distribution in male and female patients.

Malignant and premalignant lesions were more common in older age group ranging from 51 to 70 years whereas non neoplastic and benign lesions were frequently found in 31 to 40 years of age. Tongue showed more predilection for non-neoplastic lesions which comprised 26 cases (45.5\%) followed by benign (14 cases, $25 \%$ ) and malignant lesions (13 cases, $10.5 \%$ ).

Most common clinical presentation was swelling (80 cases, $63.25 \%$ ) followed by ulcer ( 34 cases, $26.25 \%$ ). Lesions presented as swelling were mostly benign and non-neoplastic in nature which constituted 36 cases (46\%) and 30 cases (39.5\%) respectively (Table 1). Most of malignant lesions presented as ulcer (18 cases, 53\%) whereas non neoplastic and benign lesions presented as swelling. Fifteen cases
$(65 \%)$ of patients with malignant lesions had habit of smoking and 5 cases (18.5\%) patients had habit of chewing gutka/paan.

The relative risk was calculated by using relative risk formula $=$ Probability of getting disease by exposed to risk factor/probability of getting disease by nonexposed. There was strong association of risk factors with malignant lesions with relative risk of 2.2 with smoking, 2.3 with gutka/paan and alcohol each and 2 with tobacco. Most common non neoplastic lesion was keratosis with no dysplasia which accounted for 22 cases $(38 \%)$, followed by mucocele which comprised 9 cases $(16 \%)$. The most common benign lesions were squamous papilloma and fibroepithelial polyp (6 cases each, 20\%), followed by pyogenic granuloma (5 cases, 16.6\%) (Table 2).

The most common premalignant lesion was low grade dysplasia which accounted for 4 cases $(45 \%)$ followed by actinic cheilitis which comprised of 3 cases each $(33 \%)$.

The most common malignant lesion was squamous cell carcinoma which comprised 28 cases (93.6\%) showing nests and lobules of atypical squamous cells, keratin pearls on histopathological examination (Figure 3) followed by adenoid cystic carcinoma comprised 2 cases (Figure 4). Out of the total 127 cases, $51(40 \%)$ clinical diagnoses correlated with histopathological diagnoses.

Table 1: Distribution of cases according to symptoms and nature of lesions.

\begin{tabular}{|l|c|c|c|c|c|}
\hline \multicolumn{1}{|c|}{ Clinical features } & Non neoplastic & Benign & Premalignant & Malignant & Total \\
\hline Swelling & 36 & 30 & 2 & 8 & $76(60 \%)$ \\
\hline Ulcer & 13 & - & 2 & 15 & $30(23 \%)$ \\
\hline Swelling+ Ulcer & - & - & 1 & 3 & $4(3.25 \%)$ \\
\hline White plaque & 5 & 1 & 3 & 4 & $13(10.55 \%)$ \\
\hline Pain & 1 & - & 1 & - & $2(1.6 \%)$ \\
\hline Red plaque & 1 & - & - & - & $1(0.8 \%)$ \\
\hline Difficult in chewing & 1 & - & - & - & $1(0.8 \%)$ \\
\hline Total & 57 & 31 & 9 & 30 & $127(100 \%)$ \\
\hline
\end{tabular}


Table 2: Table showing frequency of benign neoplastic lesions.

\begin{tabular}{|c|l|c|c|}
\hline S.N & \multicolumn{1}{|c|}{ Histopathological diagnosis } & Frequency & Percentage (\%) \\
\hline 1 & Squamous papilloma & 6 & 19.5 \\
\hline 2 & Fibroepithelial polyp & 6 & 19.5 \\
\hline 3 & Pyogenic granuloma & 5 & 16.5 \\
\hline 4 & Hemangioma & 4 & 13 \\
\hline 5 & Pleomorphic adenoma & 3 & 6.5 \\
\hline 6 & Fibroma & 2 & 6.5 \\
\hline 7 & Neurofibroma & 2 & 6.5 \\
\hline 8 & Benign fibrous histiocytoma & 1 & 3 \\
\hline 9 & Mucosal neuroma & 1 & 3 \\
\hline 10 & Verruca vulgaris & 1 & 3 \\
\hline
\end{tabular}

\section{DISCUSSION}

A diverse spectrum of oral mucosal lesions exists, presenting either as isolated oral finding or associated with other systemic or dermatological conditions. Many oral lesions can closely resemble one another and cannot be distinguished just by clinical examination, so definitive diagnosis should be established by histopathological examination.

A total of 127 patients were included in this study, among whom $66(52 \%)$ were females and $61(48 \%)$ were males with $\mathrm{M}: \mathrm{F}$ ratio of $1: 1.1$. There is no significant difference between male and female patients which is in accordance with the study done in Spain by Claudia et al. ${ }^{3}$ In contrast, study done in Kathmandu, Nepal by Pudasaini ${ }^{4}$ and Uttar Pradesh, India ${ }^{5}$ showed males predilection. Affected range of age in index study was from 2 months to 86 years with mean age being 44.24 years which is in concordance with study done at Tertiary Care Dental Hospital of Kathmandu', Lebanon?

The youngest case was 2 months female diagnosed with mucocele and the oldest one was 86 years old female diagnosed as lobular capillary hemangioma. Increased number of lesions in older age group could be due to their long standing oral habits. The main site of occurance reported in this study was tongue (45\%) followed by lip (24\%) (Figure 2) which is similar to other studies in literature ${ }^{5}$, in contrast
Wahi et al. ${ }^{8}$ and Modi et al. ${ }^{9}$ showed buccal mucosa as the commonest site.

In index study, 45 patients had habit of smoking, females (53\%) being more than males which is highly discordant with Prashant et al. ${ }^{10}$ done in Karnataka, India. Overall $33 \%$ of the smokers had malignancy in our study, which were evenly distributed in both sexes. The relative risk for smokers was 2.2. Case control study done over a period of 19 months in Pune, India showed significant risk of smoking on oral cancer with odds ratio of 4.1. ${ }^{11}$ Muwonge et al. ${ }^{12}$ found that tobacco chewing as the strongest risk factor associated with oral cancer. In the present study, common presentation of oral cavity lesions was swelling ( 80 cases, 63\%) followed by ulcer (34 cases, 27\%) (Table no 1). Likewise Rashmi et al. ${ }^{13}$ observed majority of oral cavity lesions presented as ulcer $(44.5 \%)$ followed by white plaque $(12.9 \%)$.

The present study showed equal distribution of benign lesions (24.4\%) and malignant (23.6\%) which is in accordance with study of Shamim et al. ${ }^{14}$ which showed $24.5 \%$ of malignant lesions. In contrast, Shashikala et al. ${ }^{15}$ reported $74 \%$ malignant and $26 \%$ of benign lesions. If non neoplastic, benign and premalignant lesions were clubbed together in the present study, prevalence of non-malignant increased to $76.4 \%$. This reflects overall frequent occurrence of non- malignant lesions. Current study found fibroepithelial polyp and squamous papilloma 
as the most common benign lesions each accounting for 6 cases $(19.5 \%)$. This finding is in concordance with other studies ${ }^{16,17}$ showing fibroepithelial polyp as commonest benign lesion. Second commonest benign oral lesion was pyogenic granuloma which constituted 5 cases $(16 \%)$ which was comparable with study done by Modi et al. ${ }^{9}$ and Riaz ${ }^{18}$.

Malignant lesions were more common in older age group ranging from 51-70 years which accounted for 18 cases $(60 \%)$ which was comparable with study done in Assam, India. ${ }^{19}$ This is due to clustering of cases and acquisition of risk habits was more observed in the same age group in their study. Few studies showed increased incidence of oral cancer in younger age group of 41-50 years which is slightly different from our study. ${ }^{20}$ Common site of occurrence of malignant lesion was tongue (13 cases, $43.5 \%$ ), which was followed by lip and floor of mouth ( 5 cases each, $16.5 \%$ ). Similarly, Wahid et al. ${ }^{8}$ from Pakistan showed buccal mucosa (34\%) being commonest site followed by lip (26\%) and tongue (21\%). Most of malignant lesions presented as ulcer (60\%, 18 cases), followed by swelling/ growth which constituted 11 cases $(36.5 \%)$. Similar findings were observed in various studies showing malignant lesion presented as mass or ulcer. ${ }^{21,22}$ Hence, high suspicion of malignancy should be made if patient presents with ulcer, swelling/growth or both. Of total 30 malignant cases, most common malignant lesion

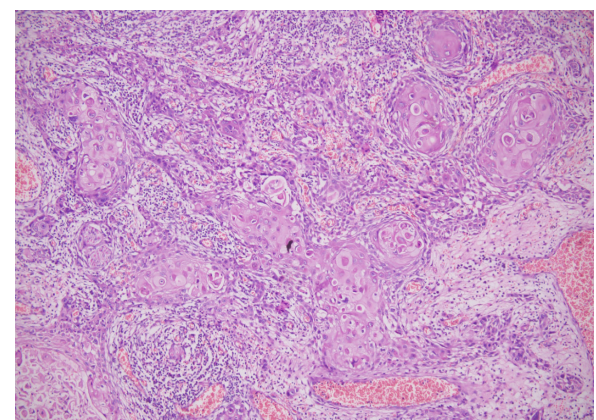

Figure 3: Squamous cell carcinoma. Nests of atypical squamoid cells with keratin pearls infiltrating the stroma (H and E stain, X200). was squamous cell carcinoma which comprised 28 cases $(93.6 \%)$. Remaining two cases were basal cell carcinoma and adenoid cystic carcinoma. Similar finding was shown by Vatsala et $\mathrm{al}^{23}$ which shows $60 \%$ of cases of squamous cell carcinoma, like wise Shubha et al., ${ }^{24}$ Ahluwalia et al. ${ }^{25}$ showed $82.7 \%$ and $89.9 \%$ of squamous cell carcinoma respectively. This infers the most common malignant lesion being squamous cell carcinoma which holds true for our study as well.

Regarding clinicopathological correlation, $60 \%$ of histopathological examinations did not correlate with clinical diagnosis. There have been varying discrepancy rates between histopathology and clinical diagnosis in various studies. Disparity in correlation between clinical and histopathological examination of oral lesions could be explained on the basis of inter-observer variation.

\section{CONCLUSIONS}

Oral cavity comprises wide spectrum of lesions varying from inflammatory to malignant. Although lesions show almost equal distribution in males and females, malignant lesions were more common in males. Tongue was most common affected site with frequent lesions were non neoplastic, clinically presented as swelling. However, malignant lesions presented as ulcer. Smoking increased risk of

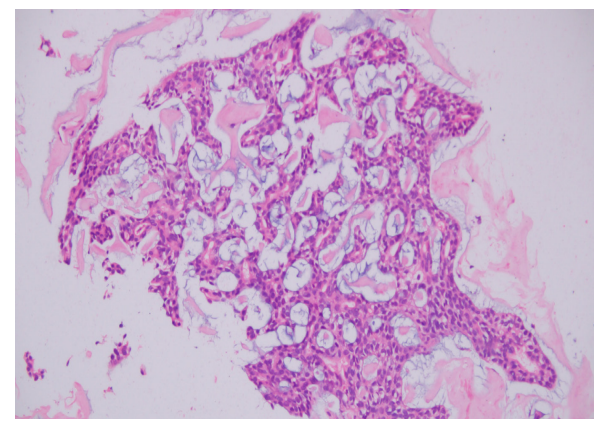

Figure 4: Adenoid cystic carcinoma of floor of mouth. Tumor composed of basaloid cells arranged in cribiform and tubular pattern (A: $H$ and $E$ stain, X40). Tumors within cribiform pattern show cystic spaces with mucinous or eosinophilic secretion (B: H and E stain, X200). 
malignant lesions by two fold. The most common benign lesions were squamous papilloma and fibroepithelial polyp whereas squamous cell carcinoma was the most common malignant lesions. Sixty percent cases showed discrepancy between clinical and pathological diagnosis which show that biopsies are an integral part of evaluating lesions.
Therefore, correlation with clinical diagnoses, site of lesions and finally histopathological examination is required for proper evaluation and treatment of patients.

\section{Conflict of Interest: None}

\section{NJHS}

\section{REFERENCES}

1. Orbak R, Bayraktar C, Kavrut F, Gündogdu C. Poor oral hygiene and dental trauma as the precipitating factors of squamous cell carcinoma. Oral Oncology Extra. 2005 Jul 1;41(6):109-13.

2. Jethwa AR, Khariwala SS. Tobacco-related carcinogenesis in head and neck cancer. Cancer Metastasis Rev. 2017 Sep;36(3):411-423. doi: 10.1007/s10555-0179689-6. PMID: 28801840; PMCID: PMC5709040.

3. Fierro- Garibay C, Almendros-Marques N, Berini Aytes L, Gay-Escoda C. Prevalence of biopsied oral lesions in a Department of Oral surgery . J CLin Exp Dent. 2011;3(2):73-7. [DOI:10.4317/jced.3.e73]

4. Pudasaini S, Baral R. Oral cavity lesions: A study of 21 cases. J Pathol Nep [Internet]. 2011 Mar. 31 [cited 2021 Nov. 17];1(1):49-51. Available from: https://www. nepjol.info/index.php/JPN/article/view/4452

5. Agrawal R, ChauhanA, Kumar P. Spectrum of Oral Lesions in A Tertiary Care Hospital. J Clin Diagn Res. 2015 Jun;9(6):EC11-3. doi: 10.7860/JCDR/2015/13363.6121 Epub 2015 Jun 1. PMID: 26266127; PMCID: PMC4525516.

6. Bajracharya D, Gupta S, Ojha B, Baral R. Prevalence of Oral Mucosal Lesions in a Tertiary Care Dental Hospital of Kathmandu. JNMA J Nepal Med Assoc. 2017 Jul-Sep;56(207):362-6. PMID: 29255321.

7. El Toum S, Cassia A, Bouchi N, Kassab I. Prevalence and Distribution of Oral Mucosal Lesions by Sex and Age Categories: A Retrospective Study of Patients Attending Lebanese School of Dentistry. Int J Dent. 2018 May 17;2018:4030134. doi: 10.1155/2018/4030134. PMID: 29887889; PMCID: PMC5985080.

8. Wahid A, Ahmad S, Sajjad M. Pattern of carcinoma of oral cavity reporting at dental department of Ayub medical college. J Ayub Med Coll Abbottabad. 2005 JanMar;17(1):65-6. PMID: 15929532.

9. Modi D, Laishram RS, Sharma LD, Debnath K. Pattern of oral cavity lesions in a tertiary care hospital in Manipur, India. J Med Soc 2013;27:199-202

10. Patil PB, Bathi R, Chaudhari S. Prevalence of oral mucosal lesions in dental patients with tobacco smoking, chewing, and mixed habits: A cross-sectional study in South India. J Family Community Med. 2013 May;20(2):130-5. doi: 10.4103/2230-8229.114777. PMID: 23983566; PMCID: PMC3748648.

11. Madani AH, Dikshit M, Bhaduri D. Risk for oral cancer associated to smoking, smokeless and oral dip products. Indian J Public Health. 2012 Jan-Mar;56(1):57-60. doi: 10.4103/0019-557X.96977. PMID: 22684175.

12. Muwonge R, Ramadas K, Sankila R, Thara S, Thomas G, Vinoda J, Sankaranarayanan R. Role of tobacco smoking, chewing and alcohol drinking in the risk of oral cancer in Trivandrum, India: a nested case-control design using incident cancer cases. Oral Oncol. 2008 May;44(5):446-54. doi: 10.1016/j.oraloncology.2007.06.002. Epub 2007 Oct 22. PMID: 17933578.

13. Goyal R, Jadia S, Jain L, Agarawal C. A Clinical Study of Oral Mucosal Lesions in Patients Visiting a Tertiary Care Centre in Central India. Indian J Otolaryngol Head Neck Surg. 2016 Dec;68(4):413-416. doi: 10.1007/s12070-015-0868-x. Epub 2015 Jun 24. PMID: 27833864; PMCID: PMC5083640.

14. Shamim T, Varghese VI, Shameena PM, Sudha S. A retrospective analysis of gingival biopsied lesions in South Indian population: 2001-2006. Med Oral Patol Oral Cir Bucal. 2008 Jul 1;13(7):E414-8. PMID: 18587304.

15. Kosam S, Kujur P. Pattern of oral cavity lesion: A retrospective study of 350 cases. Int J Sci Study. 2016, June 4(3):4. [DOI: 10.17354/ijss/2016/320]

16. Al-Khateeb TH. Benign oral masses in a Northern Jordanian population-a retrospective study. Open Dent J. 2009 Jul 28;3:147-53. doi: 10.2174/1874210600903010147. PMID: 19672335; PMCID: PMC2724667.

17. Masamatti SS, Gosavi AV, Sulhyan KR. Tumour-like lesions of oral cavity: A clinicopathological study of 95 cases. Annals of Applied Bio-Sciences. 2017 Apr 10;4(2):A83-88. [DOI:10.21276/AABS.1426]

18. Riaz N, Warraich RA. Tumors and tumor- like lesions of the oro-facial region at Mayo Hospital, Lahore- A five year study. Annals of king Edward Medical University. 2011;17(2):123.[ DOI: https://doi.org/10.21649/akemu.v17i2.285]

19. Baruah M, Bezbaruah R. Histopathological spectrum of oral lesions in a tertiary care hospital. Int J Sci Research. 2018 Aug;7(8). [PMID: 26266127/ DOI: 10.7860/ JCDR/2015/13363.6121]

20. Atram MA, Dantkale S. A clinicopathological study of tumors and tumor like lesions of oral cavity. Indian J App Basic Med Res. 2016;5(3):8. [DOI: https://doi. $\operatorname{org} / 10.17511 /$ jopm.2020.i04.01]

21. Finkelstein MW. A guide to clinical differential diagnosis of oral mucosal lesions. dentalcare com. 2010 Jul 22. [https://www.dentalcare.com/en-us/professionaleducation/ce-courses/ce110]

22. Neville BW, Day TA. Oral cancer and precancerous lesions. CA Cancer J Clin. 2002 Jul-Aug;52(4):195-215. [PMID: 12139232/ DOI: 10.3322/canjclin.52.4.195]

23. Misra V, Singh PA, Lal N, Agarwal P, Singh M. Changing pattern of oral cavity lesions and personal habits over a decade: hospital based record analysis from allahabad. Indian J Community Med. 2009 Oct;34(4):321-5. doi: 10.4103/0970-0218.58391. PMID: 20165626; PMCID: PMC2822193.

24. Bhat SP, Bhat V, Permi H, Shetty J, Aroor R, Bhandary SK. Oral and oropharyngeal malignancy: A clinicopathological study. Int J Pathol Lab Med. 2016;2(1). [https://chanrejournals.com/index.php/pathology/article/view/129/html]

25. Ahluwalia H, Gupta SC, Singh M, Gupta SC, Mishra V, Singh PA, Walia DK. Spectrum of Head-Neck cancers at Allahabad. Indian J Otolaryngol Head Neck Surg. 2001 Jan;53(1):16-21. doi: 10.1007/BF02910972. PMID: 23119744; PMCID: PMC3450883. 